\title{
Study on determination method of hydrodynamic coefficient of Marine pile foundation
}

\author{
Jiang Zongnan ${ }^{1, *}$ \\ ${ }^{1}$ College of Civil Engineering and Architecture, Shandong University of Science and Technology, 266590, Qingdao, Shandong, China
}

\begin{abstract}
The irregular waves are simulated by using standard spectrum. Instantaneous value method, Fourier analysis method, least square method and "harbour hydrological code" are used to determine the moment force of coefficient $C_{\mathrm{M}}$ and drag coefficient $C_{\mathrm{D}}$. Then $C_{\mathrm{M}}$ and $C_{\mathrm{D}}$ that linearized by Borgman L.E. equation are substituted into Morison equation. The time history curve of the wave force on the pile is calculated and compared with the measured wave force data under the action of irregular wave to analyze the advantages and disadvantages of several methods to determine $C_{\mathrm{M}}$ and $C_{\mathrm{D}}$. The results show that the comparison between $C_{\mathrm{M}}$ and $C_{\mathrm{D}}$ determined by Fourier analysis and least square method is practical.
\end{abstract}

\section{Introduction}

Pile foundation structure is a structure form suitable for offshore waters in offshore wind power foundation [1]. In the calculation of stability of pile foundation, the calculation of wave force is crucial. At present, Morison equation is generally used to calculate the wave force of small diameter pile, and the key is to reasonably determine the moment force coefficient $C_{\mathrm{M}}$ and the drag force coefficient $C_{\mathrm{D}}$ [2].

Sarpkaya[3] found through experiments that $C_{M}$ and $C_{\mathrm{D}}$ depended on $\mathrm{Re}$ number and $\mathrm{KC}$ number, and gave the rule that $C_{\mathrm{M}}$ and $C_{\mathrm{D}}$ changed with $\mathrm{KC}$ number.

$\mathrm{Yu}$ yuxiu [4] studied the wave forces acting on the isolated pile by regular waves and irregular waves, and summarized the changing relation curves of $C_{\mathrm{M}}, C_{\mathrm{D}}$ and KC Numbers.

At present, there are three main ways to determine $C_{\mathrm{M}}$ and $C_{\mathrm{D}}$. One is to use instantaneous value to calculate the number $C_{\mathrm{M}}$ and $C_{\mathrm{D}}$, the other is to use Fourier analysis method, the third is to use the least square method to calculate. In this paper, the advantages and disadvantages of these three calculation methods were analyzed by comparing the measured wave force data of pile body under the action of irregular waves with the $C_{\mathrm{M}}$ and $C_{\mathrm{D}}$ stipulated in the harbour hydrological code [5].

\section{Determination of moment force coefficient and drag force coefficient}

\subsection{Instantaneous values of $C_{M}$ and $C_{D}$}

According to the Airy wave theory, when $\cos \omega t=0$, velocity $\mathrm{u}=0$ and acceleration $a$ has an extreme value. When $\sin \omega t=0$, acceleration $a=0$ and velocity $u$ has extreme value. The instantaneous wave force data can be used to calculate the value of $C_{\mathrm{M}}$ and $C_{\mathrm{D}}$.

This method is simple to calculate, but it is necessary to ensure that one of the two values of velocity and acceleration of the instantaneous data is the extreme value and the other is 0 . Due to the nonlinear effect of waves, this condition may not be true. In addition, some irregularities of the observed data should be taken into account. In order to reduce the error caused by this irregularity, sometimes multiple values are taken for a small segment of the instantaneous vicinity and averaged after analysis.

\subsection{Fourier analysis calculates $C_{M}$ and $C_{D}$}

In stable flow, experiment is proved that $C_{\mathrm{M}}$ and $C_{\mathrm{D}}$ are functions of Reynolds number (Re), while Reynolds number changes periodically in wave motion. Keulegan and Carpenter of the United States found that the coefficients $C_{\mathrm{M}}$ and $C_{\mathrm{D}}$ were related to the ratio of drag force and moment force, and defined the $\mathrm{KC}$ number as

$$
K C=\frac{U_{\max } T}{D}
$$

Where, $U_{\max }$ is the maximum velocity of wave water point movement, $T$ is the wave period.

At present, it is believed that the coefficients $C_{\mathrm{M}}$ and $C_{\mathrm{D}}$ are related to $\mathrm{Re}$ and $\mathrm{KC}$ in the fluctuating water flow.

Keulegan and Carpenter proposed that since the velocity and acceleration in the wave current all change periodically with time, $C_{\mathrm{M}}$ and $C_{\mathrm{D}}$ should also be considered uniformly in a period. In other words, the mean value can be taken by Fourier analysis method in a period, which is called the mean value of Fourier analysis. They believe that the wave force should be an odd function, that is, a different sign within a half period:

$$
F(\theta)=-F(\theta+\pi)
$$

\footnotetext{
* Corresponding author:experience1193@126.com
} 


$$
\begin{gathered}
\frac{2 F}{\rho D U_{m}{ }^{2}}=2\left(A_{1} \sin \theta+A_{3} \sin 3 \theta+A_{5} \sin 5 \theta+\cdots\right. \\
\left.+B_{1} \cos \theta+B_{3} \cos 3 \theta+B_{5} \cos 5 \theta+\cdots\right)
\end{gathered}
$$

The expression corresponding to Morrison equation can be written as follows:

$$
\begin{gathered}
\frac{2 F}{\rho D U_{m}{ }^{2}}=\frac{\pi^{2}}{K C} C_{M} \sin \theta+2\left(A_{3} \sin 3 \theta+A_{5} \sin 5 \theta+\cdots\right) \\
-C_{D}|\cos \theta| \cos \theta+2\left(B_{3} \cos 3 \theta+B_{5} \cos 5 \theta+\cdots\right) \\
U=-U_{m} \cos \theta
\end{gathered}
$$

Take the same terms as Morrison equation, get:

$$
\frac{2 F}{\rho D U_{m}{ }^{2}}=\frac{\pi^{2}}{K C} C_{M} \sin \theta-C_{D}|\cos \theta| \cos \theta
$$

It should be noted that $C_{\mathrm{M}}$ and $C_{\mathrm{D}}$ are considered to be independent of $\theta$, and they are a constant when the Re Numbers and KC Numbers are known, and when $\mathrm{n}>3$, the terms $A_{\mathrm{n}}$ and $B_{\mathrm{n}}$ are all 0 .

Multiply both sides of equation (6) by $\cos \theta$ and integrate $\theta$ in the range of $(0,2 \pi)$

$$
C_{D}=-\frac{3}{4} \int_{0}^{2 \pi} \frac{F \cos \theta}{\rho D U_{m}{ }^{2}} d \theta
$$

Multiply both sides of equation (6) by $\sin \theta$ and integrate $\theta$ in the range of $(0,2 \pi)$

$$
C_{M}=\frac{2 U_{m} T}{\pi^{3} D} \int_{0}^{2 \pi} \frac{F \sin \theta}{\rho D U_{m}{ }^{2}} d \theta
$$

From the above two equations, the mean values of $C_{\mathrm{M}}$ and $C_{\mathrm{D}}$ obtained by Fourier analysis can be obtained.

\subsection{The least square method calculates $C_{M}$ and $C_{D}$}

Set $F_{\mathrm{m}}$ as instantaneous measured value, $F_{\mathrm{c}}$ as the calculated value of action, $E$ as its error, so the total error is

$$
E^{2}=\left(F_{m}-F_{c}\right)^{2}
$$

According to the principle of least square method, the selected $C_{\mathrm{M}}$ and $C_{\mathrm{D}}$ values should meet the following

\begin{tabular}{|c|c|c|c|c|}
\hline & $\begin{array}{c}\text { API } \\
\text { (USA) }\end{array}$ & $\begin{array}{c}\text { DNV } \\
\text { (Norway) }\end{array}$ & $\begin{array}{c}\text { DTI } \\
\text { (USA) }\end{array}$ & $\begin{array}{c}\text { Harbour } \\
\text { hydrological } \\
\text { code(Chian) }\end{array}$ \\
\hline$C_{\mathrm{D}}$ & $0.6 \sim 1.0$ & $0.5 \sim 1.2$ & \multirow{2}{*}{$\begin{array}{l}\text { Use the } \\
\text { reliable test }\end{array}$} & 1.2 \\
\hline$C_{\mathrm{M}}$ & $1.5 \sim 2.1$ & 2.0 & & 2.0 \\
\hline
\end{tabular}
conditions:

$$
\left\{\begin{array}{l}
\frac{d E^{2}}{d C_{D}}=0 \\
\frac{d E^{2}}{d C_{M}}=0
\end{array}\right.
$$

\subsection{Recommended values for $C_{M}$ and $C_{D}$ for national specifications}

Table 1 shows the recommended values of $C_{\mathrm{M}}$ and $C_{\mathrm{D}}$ for national norms [7].

Table 1. National specification
As can be seen from table 1, the definitions of $C_{\mathrm{M}}$ and $C_{\mathrm{D}}$ vary from country to country. The API defines different $C_{\mathrm{M}}$ and $C_{\mathrm{D}}$ values for the roughness or smoothness of rods. There is no domestic regulation on the smoothness of cylinders, and the values are relatively conservative.

\section{Calculation of wave elements}

\subsection{Instantaneous values of $C_{M}$ and $C_{D}$}

\subsubsection{The wave spectrum}

Random wave is closely related to the selection of frequency, and frequency is closely related to wave characteristics such as wave height and wave frequency. Practical marine spectral materials are drawn according to a large number of measured statistics. The corresponding random wave loads are fitted to reflect the wave conditions in a similar real environment. In order to reflect the actual wave force of the offshore fan, the wave spectrum of China is adopted here [8]. Its form is:

$$
S(\omega)=\frac{0.74}{\omega^{5}} \exp \left(-\frac{2.46}{\omega^{2} H_{S}}\right)
$$

Where: $\omega$ is circular frequency. $H_{\mathrm{S}}$ is the effective wave height of random wave.

\subsubsection{Wave equation}

Considering the wave as a stationary random process, it is assumed that the wave is composed of several linear waves with different frequencies, amplitudes, wave Numbers and initial random phases. The form of any constituent wave is as follows:

$$
\eta_{i}(t)=A_{i} \cos \left(k_{i} x-\omega_{i} t+\varepsilon_{i}\right)
$$

Where, $\eta(t)$ is the wave equation. $A_{\mathrm{i}}$ is the amplitude of any constituent wave. $k_{\mathrm{i}}$ is the wave number of any constituent wave. $\omega_{\mathrm{i}}$ is the circular frequency of any constituent wave. $\varepsilon_{\mathrm{i}}$ is the initial random phase of any constituent wave, and its value is averaged at $[0,2 \pi]$.

In the equation (12), there is a corresponding relation between wave number and circular frequency, that is, the dispersion relation. According to the free surface condition, they are mutually constrained, and their relationship is as follows:

$$
\omega^{2}=g k \tanh k d
$$

Where $d$ is water depth. In the case of infinite water depth, $d$ goes to infinity, and the dispersion relation is:

$$
\omega^{2}=g k
$$

According to Airy wave theory, using the harmonic superposition method, the wave surface time history equation of the random wave is as follows:

$$
\begin{gathered}
\eta(t)=\sum_{i=1}^{M} a_{i} \cos \left(\omega_{i} t+\varepsilon_{i}\right) \\
\omega_{n}=\frac{\omega_{i+1}+\omega_{i}}{2}
\end{gathered}
$$




$$
\begin{gathered}
\Delta \omega=\omega_{i+1}-\omega_{i} \\
a_{i}=\sqrt{2 S\left(\omega_{n}\right) \Delta \omega}
\end{gathered}
$$

Velocity time history equation and acceleration time history equation at any depth $d$ :

$$
\begin{aligned}
& u(t)=\sum_{i=1}^{M} a_{i} \omega_{i} \frac{\cosh \left(k_{i} z\right)}{\sinh \left(k_{i} d\right)} \cos \left(\omega_{i} t+\varepsilon_{i}\right) \\
& a(t)=\sum_{i=1}^{M} a_{i} \omega_{i}^{2} \frac{\cosh \left(k_{i} z\right)}{\sinh \left(k_{i} d\right)} \cos \left(\omega_{i} t+\varepsilon_{i}\right)
\end{aligned}
$$

\subsection{Calculation method of wave force}

In marine engineering, Morison equation is often used to calculate the wave force of small diameter pile. Morison equation was proposed by Morison et al., university of California, Berkeley in 1950. It is a semi-theoretical and semi-empirical formula. The method considers that the wave force on the structure can be divided into two parts: the velocity force caused by the velocity of the wave particle and the moment force caused by the acceleration of the wave particle. The wave force acting on the pile with unit length is expressed as follows:

$$
f(t)=\frac{1}{2} C_{D} \rho D u(t)|u(t)|+\frac{1}{4} C_{M} \rho \pi D^{2} a(t)
$$

Where, $C_{\mathrm{D}}$ is the drag force coefficient. $C_{\mathrm{M}}$ is the moment force coefficient. $\rho$ is the density of seawater. $D$ is the diameter of single pile.

It is not difficult to find from the equation (21) that the drag force is non-linear, so it needs to be linearized through Borgman L.E equation, and the results are as follows:

$$
\begin{gathered}
u(t)|u(t)|=\sigma_{u} \sqrt{\frac{8}{\pi}} \cdot u(t) \\
\sigma_{u}{ }^{2}=\int_{\omega_{1}}^{\omega_{2}} S(\omega) d \omega
\end{gathered}
$$

$\sigma_{u}$ is the key to linearization, and the value of the upper and lower limits of the integral in its calculation formula should refer to the actual project.

In practical calculation, several linear waves of different sizes can be formed by dividing the truncated frequency into segments by the equal-frequency method.

\subsection{Project profile}

\subsubsection{Basic situation}

Shanghai East China Sea bridge 100MW offshore wind power demonstration project is located in the east sea area of Shanghai East China Sea bridge, with a total installed capacity of 102MW. 34 SL3000 offshore wind turbines with a capacity of $3 \mathrm{MW}$ per unit are installed. $D=1.7 \mathrm{~m}$ in diameter and $20.6 \mathrm{~m}$ in depth.

\subsubsection{Hydrologic condition}

The characteristic values of tidal level are shown in Table 2. And Table 3 shows design wave elements.
Table 2. Characteristics of tidal level (national 85 elevation)

\begin{tabular}{|c|c|}
\hline Mean sea level (m) & 0.23 \\
\hline Mean high water (m) & 1.86 \\
\hline Mean low water (m) & -1.34 \\
\hline Design high water level (m) & 2.55 \\
\hline Design low water level (m) & -2.09 \\
\hline Extreme high water level (m) & 3.68 \\
\hline Extreme low water level (m) & -2.93 \\
\hline
\end{tabular}

Table 3. Design wave elements

\begin{tabular}{|c|c|c|c|}
\hline $\begin{array}{c}\text { Recurrence } \\
\text { interval (year) }\end{array}$ & $\begin{array}{c}\text { Average } \\
\text { wave height } \\
\text { (m) }\end{array}$ & $\begin{array}{c}\text { Mean wave } \\
\text { period (s) }\end{array}$ & $\begin{array}{c}\text { Wave } \\
\text { length (m) }\end{array}$ \\
\hline 50 & 2.83 & 7.76 & 74.1 \\
\hline $\boldsymbol{H}_{\mathbf{1} \%(\mathbf{m})}$ & $\boldsymbol{H}_{\mathbf{4} \%(\mathbf{m})}$ & $\boldsymbol{H}_{\mathbf{5} \%}(\mathbf{m})$ & $\boldsymbol{H}_{\mathbf{1 3} \%(\mathbf{m})}$ \\
\hline 5.81 & 5.06 & 4.92 & 4.24 \\
\hline
\end{tabular}

\section{Analysis of computing result}

\subsection{Time history curve of each wave element}

Figure 1 is the wave spectrum diagram.

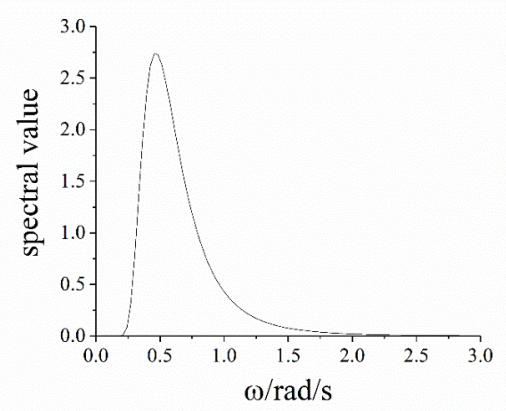

Fig.1. Wave spectrum diagram

As can be seen from figure 1, the change of spectral value after the circular frequency reached 2.5 was almost small, so $0.2<\omega<2.5$ was taken for calculation.

According to the calculation method in part 3.1, the time history curve of the wave equation is shown in Figure 2, and the time history curve of the velocity and acceleration of the water point is shown in Figure 3 and Figure 4. 


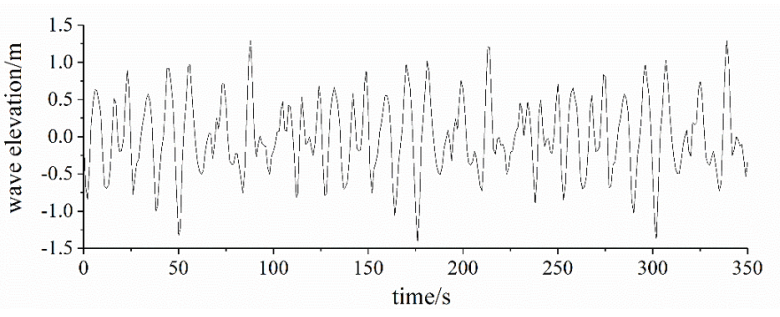

Fig.2. Time history curve of random wave wave surface

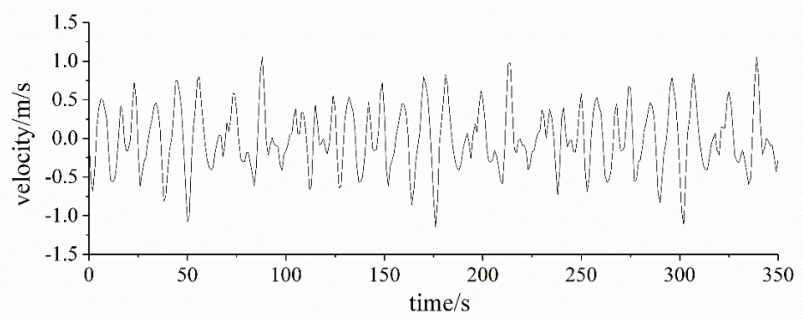

Fig.3. Velocity time-history curve

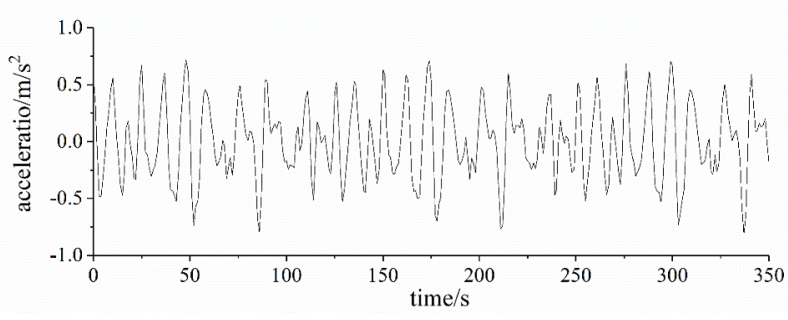

Fig.4. Acceleration time history curve

\subsection{Analysis of computing result}

$C_{\mathrm{M}}$ and $C_{\mathrm{D}}$ determined by instantaneous value method, Fourier analysis method, least square method and "harbour hydrological code" are shown in Table 4.

Table 4. Values of $C_{\mathrm{M}}$ and $C_{\mathrm{D}}$

\begin{tabular}{|c|c|c|}
\hline & $\boldsymbol{C}_{\mathrm{D}}$ & $\boldsymbol{C}_{\mathrm{M}}$ \\
\hline Harbour hydrological code & 1.2 & 2 \\
\hline Least square method & 0.58 & 1.42 \\
\hline Fourier analysis method & 0.62 & 1.56 \\
\hline Instantaneous value method & 0.81 & 1.12 \\
\hline
\end{tabular}

According to $C_{\mathrm{M}}$ and $C_{\mathrm{D}}$ determined by the above methods, the time history curve obtained by substituting into Morison equation is calculated and compared with the measured wave force data on the pile, as shown in Figure 5.

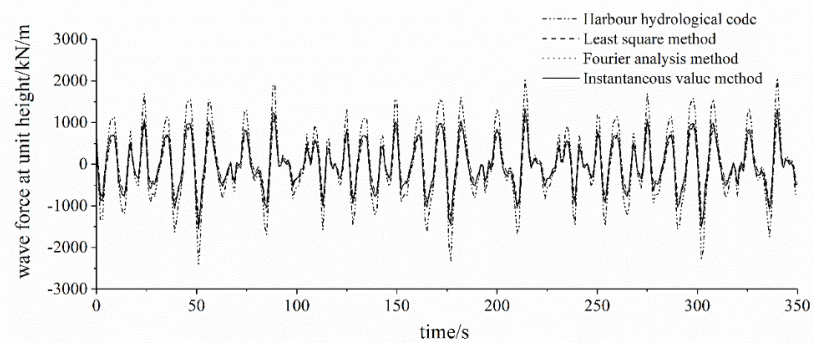

Fig.5. Time history curve of wave force at unit height
It can be seen from the Figure. 5 that the values of $C_{\mathrm{M}}$ and $C_{\mathrm{D}}$ determined by the instantaneous value method.

The harbour hydrological code are quite different from the measured values, while the values of $C_{M}$ and $C_{\mathrm{D}}$ calculated by the Fourier analysis method and the least square method are quite close to the measured values.

\section{Conclusion}

The values of $C_{\mathrm{M}}$ and $C_{\mathrm{D}}$ calculated by the instantaneous value method have a large error because the conditions for their values are too harsh and the actual situation is not quite in line with the calculation principle. However, the values of $C_{\mathrm{M}}$ and $C_{\mathrm{D}}$ stipulated in the harbour hydrological code are relatively conservative, and the drag force and moment force calculated according to the domestic code are larger than the measured value. The values of $C_{\mathrm{M}}$ and $C_{\mathrm{D}}$ calculated by Fourier analysis method and least square method are close to the measured values.

\section{References}

1. Y. C. Li. The new development of offshore engineering technology. China Offshore Platform, 13(1), 9-12 (1998)

2. X. J. Yao, F. K. Gui, A. Meng, et al. Experimental study on hydro-coefficients of horizontal cylinder structure in waves. The Ocean Engineering, 34(1), 80-87 (2016)

3. T. Sarpkaya. Forces on cylinders and spheres in a sinusoidally oscillating Fluid. Journal of Applied Mechanics, 42, 32-37 (1975)

4. Y. X. Yu, N. C. Zhang. The positive force of irregular wave on vertical pile. Acta Oceanologica Sinica, 10(5), 609-617 (1988)

5. JTS 145-2015, Code of hydrology for harbor and waterway.

6. W. W. Yao. An engineering approach for computation of wave loads on pile-slab structures. Shanghai Jiaotong University. (2009)

7. Z. Z. Qiu, J. B. Liu, H. Dai. Experiment research on wave load of high-capped-pile foundation. China Harbour Engineering, 37(02), 48-52 (2017)

8. H. R. Dong. Study on dynamic response of steel pipe pile-soil interaction under random wave load. Yanshan University. (2014) 